\title{
Corneal and conjunctival sensitivity to air stimuli
}

\author{
F Stapleton, M E Tan, E B Papas, K Ehrmann, B Golebiowski, J Vega, B A Holden
}

Br J Ophthalmol 2004;88:1547-1551. doi: 10.1136/bjo.2004.044024

See end of article for authors' affiliations

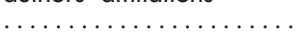

Correspondence to: Dr Fiona Stapleton, Vision CRC, University of New South Wales, Sydney

New South Wales, 2052

Australia; F.Stapleton@

visioncrc.org

Accepted for publication 25 May 2004

\begin{abstract}
Aims: To determine the repeatability of ocular surface sensitivity to mechanical stimulation using air stimuli and the effect of contact lens (CL) wear on sensitivity.

Methods: Repeatability: 14 subjects (24-39 years) participated. Mechanical sensitivity to warmed $\left(34^{\circ} \mathrm{C}\right)$ and ambient $\left(20^{\circ} \mathrm{C}\right)$ air was measured for the central cornea $(\mathrm{CC})$, inferior cornea $(\mathrm{IC})$, and inferior conjunctiva (ICON). Measurements were taken on 12 days; six morning and six afternoon measurements. Differences between sites, time of day, and stimulus temperature were evaluated. $C L$ wear: 10 subjects (22-30 years) participated. Measurements were taken at the same time of day, either following no wear, wear of a CL of oxygen permeability [Dk] of $28 \times 10^{-9}[\mathrm{~cm} / \mathrm{s}][\mathrm{ml} \mathrm{O} / 2 \mathrm{ml} \mathrm{mm} \mathrm{Hg}$ ] or wear of a CL of Dk $140 \times 10^{-9}[\mathrm{~cm} / \mathrm{s}]\left[\mathrm{ml} \mathrm{O}_{2} / \mathrm{ml} \mathrm{mm} \mathrm{Hg}\right.$. Differences between sites and wear conditions were evaluated. Results: Repeatability: Sensitivity varied between sites $(p<0.01)$, time of day $(p<0.05)$, and stimulus temperatures $(p<0.01)$. There were no significant differences between days. Mean thresholds for eye temperature stimuli were; CC 64.4 (SD 28.6) $\mathrm{ml} / \mathrm{min} ; \mathrm{IC} 84.6(40.0) \mathrm{ml} / \mathrm{min} ; \mathrm{ICON} 120.6(40.4) \mathrm{ml} / \mathrm{min}$ and for ambient temperature stimuli were CC $53.9(16.0) \mathrm{ml} / \mathrm{min}$, IC $59.0(20.0) \mathrm{ml} / \mathrm{min} ;$ ICON 72.6 (43.7) $\mathrm{ml} / \mathrm{min}$. Cl wear: Sensitivity varied between sites and wear conditions $(p<0.05)$. Conjunctival sensitivity was increased after wear of highly oxygen permeable CLs but unaffected by wear of low oxygen permeable CLs.

Conclusions: The prototype gas aesthesiometer is able to repeatably measure ocular surface sensitivity and measurements are consistent with previously reported techniques.
\end{abstract}




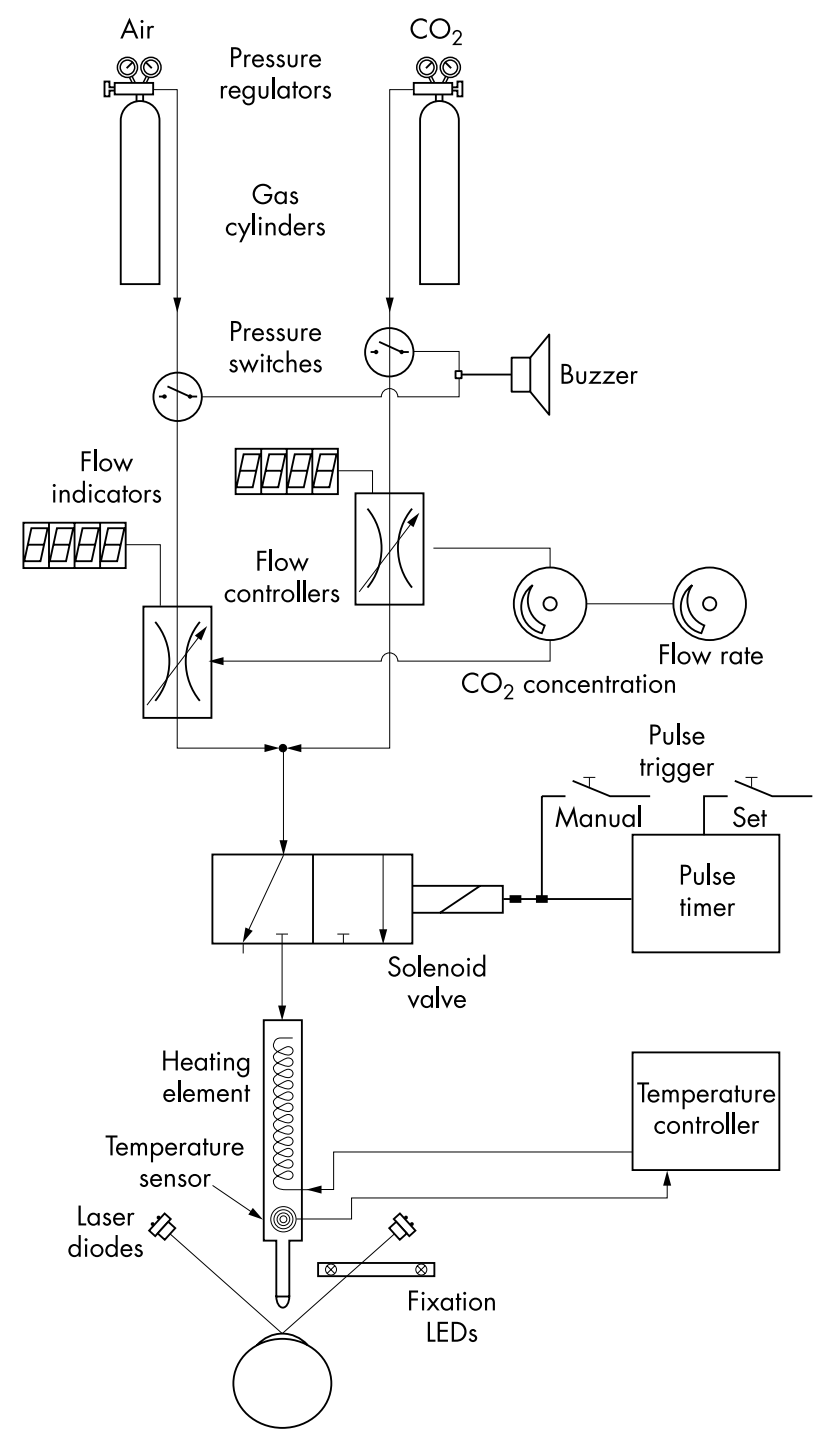

Figure 1 A schematic view of the modified gas aesthesiometer.

gas, and a three way solenoid valve to direct the output of gas. The effective temperature of the stimulus on the eye can be varied between room temperature $\left(20^{\circ} \mathrm{C}\right)$ and $34^{\circ} \mathrm{C}$. The temperature sensor provides feedback to maintain a steady temperature independent of air flow and ambient temperature. The effective on-eye temperature was calibrated across the range of available flow rates (fig 2), for nominal temperatures of $20^{\circ} \mathrm{C}$ and $34^{\circ} \mathrm{C}$. There was no significant temperature variation across flow rates $(\mathrm{p}>0.05)$ and there was no demonstrable reduction in temperature or increased variability with increased flow rates for 1 second and 2 second pulse durations. The stimulus temperatures were selected to provide a mechanical stimulus without a thermally cooling effect $\left(34^{\circ} \mathrm{C}\right)$ and a mechanical stimulus with maximum cooling effect $\left(20^{\circ} \mathrm{C}\right)$. Using the current instrument design without an additional cooling device, air pulses could not be delivered at temperatures lower than $20^{\circ} \mathrm{C}$.

During stimulation, the gas is transiently directed towards the tip of the probe by means of a pulse generator that changes the direction of flow in the electronic valve. This produces a pulse of gas in the tip of the probe with a defined duration, $\mathrm{CO}_{2}$ concentration, temperature, and flow rate. Stimulus duration ranged between $1-3$ seconds with a

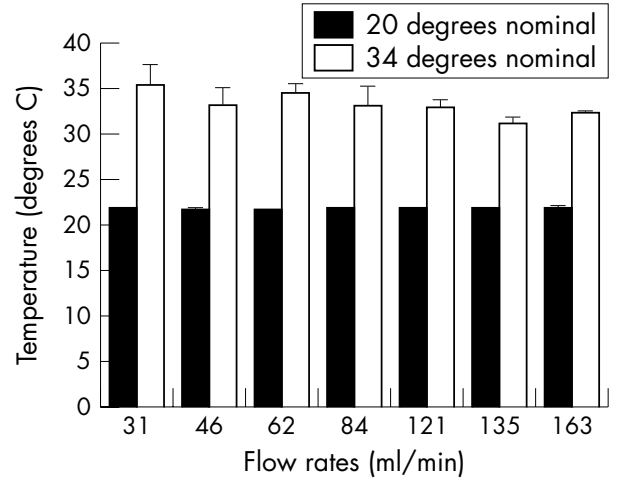

Figure 2 Temperature variation with flow rate for nominal on-eye temperatures of $20^{\circ} \mathrm{C}$ and $34^{\circ} \mathrm{C}$.

precision of 0.1 second. The optical range finder in the probe housing was modified to maintain an alignment distance between the probe and the eye of $4 \mathrm{~mm}$. Two laser pointers assist with finding the correct working distance when stimulating non-reflective locations on the ocular surface and moveable fixation lights mounted on the instrument housing enabled alteration of stimulus location.

Using a flow rate of $240 \mathrm{ml} /$ minute, using air at $34^{\circ} \mathrm{C}$ with a 1 second pulse duration, the stimulus size at $4 \mathrm{~mm}$ from the probe was $0.5 \mathrm{~mm}$ central diameter corresponding to the region of highest pressure. The pressure profile across the cornea appeared to show a Gaussian distribution, with decrease in pressure outside this region. Disturbance in the fluorescein pattern on the eye was detectable in the surrounding region to a diameter of $1.5 \mathrm{~mm}$. The effect of stimulus delivery for these conditions on the eye is shown in figure 3; however, the precise characteristics of the stimulus footprint on eye under a range of flow rate and temperature conditions are yet to be fully elucidated.

\section{Subjects}

For the repeatability study, 14 normal non-contact lens wearers participated. Subjects were 12 females and two males, with a mean age of 32 (SD 6) years (range 24-39). Ten subjects participated in the contact lens wear study. This group comprising five males and five females with a mean age of 24 (3) years (range 21-30) participated. No subject had a history of ocular pathology or systemic disease. This investigation was conducted in accordance with the tenets of the Declaration of Helsinki. Written consent was obtained following explanation of the study procedures. University of

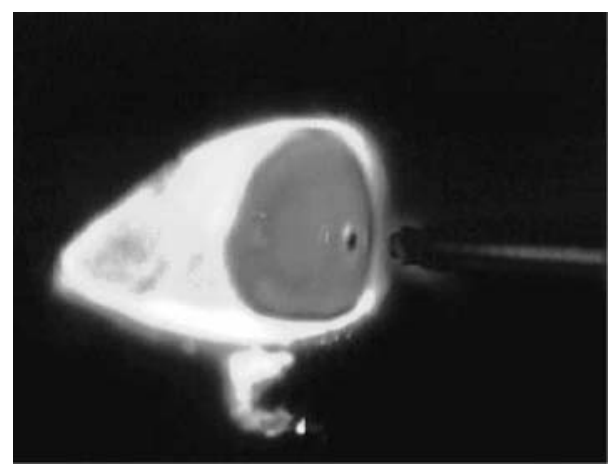

Figure 3 Aesthesiometer stimulus delivery on the eye for $240 \mathrm{ml} /$ minute flow rate and 1 second delivery. The probe tip is visible and the stimulus location is shown by the disruption in the tear film shown with fluorescein. 
New South Wales ethics committee approval for the procedures was also obtained before the investigation.

\section{Procedures}

One second air pulses (flow rates $21-240 \mathrm{ml} / \mathrm{min}$ ) with an on-eye temperature of either $20^{\circ} \mathrm{C}$ or $34^{\circ} \mathrm{C}$ were delivered to the right eye of each subject to the corneal apex (central cornea), to the inferior cornea at a position $2 \mathrm{~mm}$ vertically above a tangent to the inferior limbus, and to the inferior conjunctiva, $2 \mathrm{~mm}$ vertically below a tangent to the inferior limbus. The inferior cornea and conjunctiva were selected as being the regions potentially susceptible to the effects of exposure or tear film instability in contact lens wear or dry eye disease.

Thresholds to mechanical stimulation were determined by the method of constant stimuli and by using a logistic response function (Curve Expert 1.3, Daniel Hyams). Subjects were asked to respond verbally as to whether the stimulus had been detected or not. The flow rate corresponding to $50 \%$ positive response rate was determined $\left(\mathrm{T}_{50}\right)$. The order of presentations for different flow rates and ocular sites was randomised within each occasion, and a minimum of 1 minute was allowed between repeated stimulation of the same site, to limit summation or adaptation. Randomisation for temperature of stimulus presentation was not possible within occasions, since a 20 minute period is required for full equilibration following change of stimulus temperature. The subject was masked to the order of stimulus presentation, but not to location tested.

For the repeatability study, measurements were taken on 12 separate occasions, six in the morning (10 am plus or minus 1 hour) and six in the afternoon ( 3 pm plus or minus 1 hour). Temperature and humidity of the laboratory were recorded for each measurement. Mean (SD) humidity and temperature was $40.0 \%(8.3 \%)$ and $24.2(0.6)^{\circ} \mathrm{C}$, respectively.

In the CL wear study, measurements were taken on three separate occasions, each in the afternoon. Stimuli were delivered as above; however, ocular sites for the right eye were examined with stimuli delivered at $34^{\circ} \mathrm{C}$ only. On one occasion, subjects were tested without previous CL wear, and on the remaining two occasions, testing followed either 6 hours bilateral wear of disposable Etafilcon A lenses (Vistakon, Johnson \& Johnson, Jacksonville, FL, USA) of power -1.00 dioptres, back optic zone radius of $8.80 \mathrm{~mm}$, diameter $14.0 \mathrm{~mm}$, water content $58 \%$, and material oxygen permeability of $28 \times 10^{-9}[\mathrm{~cm} / \mathrm{s}]\left[\mathrm{ml} \mathrm{O}_{2} / \mathrm{ml} \mathrm{mm} \mathrm{Hg}\right]$ or bilateral wear of Lotrafilcon A silicone hydrogel lenses (CibaVision, Duluth, AT, USA), of power -1.00 dioptres, back optic zone radius $8.60 \mathrm{~mm}$, diameter $13.80 \mathrm{~mm}$, water content $24 \%$ and material oxygen permeability of $140 \times 10^{-9}$

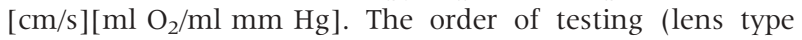
or no lens wear) was randomised. Mean (SD) humidity and temperature was $54 \%(7 \%)$ and $24(0.6)^{\circ} \mathrm{C}$ (CL wear study).

\section{Data analysis}

Analysis of variance (ANOVA) was carried out on the entire data set using time of day and day as within subject factors and location and stimulus temperature as between subject factors (SPSS for windows, version 10.0.07, Chicago, IL, USA). A multiple comparisons test with Bonferroni adjustment was used to determine differences between ocular sites. Coefficients of repeatability $(1.96 \times$ within subjects standard deviation) were estimated for each ocular site.

One way ANOVA was carried out on the CL wear data to determine differences between CL wear conditions and a multiple comparisons test with Bonferroni adjustment was used to determine differences.

\section{RESULTS}

\section{General results}

Mean and standard deviations for $\mathrm{T}_{50}$ measurements at each ocular site for the two stimulus temperatures for morning and afternoon measurements are shown in table 1.

\section{Day to day and diurnal variability}

The sensitivity data were seen to meet the assumptions for ANOVA, such that the data exhibited a normal distribution and the sensitivity measurements taken on different occasions showed similar variance. ANOVA revealed no significant difference in sensitivity between days $(p>0.05$, power to detect differences was 0.52 ). Time of day significantly affected sensitivity for the central and inferior cornea for stimuli delivered at $34^{\circ} \mathrm{C}(\mathrm{p}<0.001)$, with higher sensitivity found for afternoon measurements. Conjunctival sensitivity was unaffected by time of day and all measurements taken at $20^{\circ} \mathrm{C}$ did not demonstrate diurnal variations. The majority of variation in sensitivity measurements occurred between subjects and coefficients of repeatability ranged between $16-36 \mathrm{ml} / \mathrm{min}$ (table 1 ). In general, better repeatability was observed for afternoon measurements and for the lower stimulus temperature.

\section{Ocular site and stimulus temperature}

ANOVA showed significant differences in sensitivity between ocular sites and between stimulus temperatures $(\mathrm{p}<0.01$, table 2). Sensitivity for low temperature stimuli was higher than for the eye temperature stimuli. Post hoc testing showed that corneal sensitivity was significantly higher than conjunctival sensitivity $(\mathrm{p}<0.01)$; however, differences between the central and inferior cornea were not significant.

\section{Effects of short term contact lens wear}

The sensitivity data were seen to meet the assumptions for ANOVA, such that the data exhibited a normal distribution and the sensitivity measurements for different conditions showed similar variance. However, there were interactions between ocular site and lens factors, hence one way ANOVAs between lens wear conditions were carried out for each site. Table 3 shows the summary data for each site and lens type.

\begin{tabular}{|c|c|c|c|c|}
\hline $\begin{array}{l}\text { Stimulus } \\
\text { temperature }\end{array}$ & Time of day & Central cornea [COR] & Inferior cornea [COR] & Inferior conjunctiva [COR] \\
\hline $20^{\circ} \mathrm{C}$ & Mean am $/ \mathrm{pm}$ & $53.9(16.0)$ & $59.0(20.0)$ & $72.6(43.7)$ \\
\hline $20^{\circ} \mathrm{C}$ & & $53.6(15.8)[17.2]$ & $57.4(21.0)[18.6]$ & $71.5(46.2)[26.7]$ \\
\hline $20^{\circ} \mathrm{C}$ & $\mathrm{pm}$ & $54.2(17.5)[16.1]$ & $60.6(20.6)[19.0]$ & $73.7(41.8)[25.9]$ \\
\hline $34^{\circ} \mathrm{C}$ & Mean am $/ \mathrm{pm}$ & $64.4(28.6)$ & $84.6(40.0)$ & $120.6(40.4)$ \\
\hline $34^{\circ} \mathrm{C}$ & am & $68.3(30.0)[23.6]$ & $87.9(40.0)[27.0]$ & 119.2 (43.7) [35.5] \\
\hline $34^{\circ} \mathrm{C}$ & $\mathrm{pm}$ & $60.6(28.9)[20.4]$ & $81.2(40.8)[27.0]$ & $122.0(38.9)[29.4]$ \\
\hline
\end{tabular}


Table 2 ANOVA results for between subjects effects

\begin{tabular}{lllll}
\hline & $\begin{array}{c}\text { Type III sum } \\
\text { of squares }\end{array}$ & df & F & p Value \\
\hline Ocular site & 130835 & 2 & 5.879 & 0.004 \\
Temperature & 93217 & 1 & 8.377 & 0.005 \\
Location $\times$ temperature & 62498 & 2 & 2.808 & 0.067 \\
\hline
\end{tabular}

Lens wear conditions did not affect corneal sensitivity; however, there were differences in conjunctival sensitivity between wear conditions (ANOVA, $\mathrm{p}<0.05$ ). The conjunctiva was significantly more sensitive following wear of Lotrafilcon lenses compared to either no lens wear or Etafilcon lens wear $(\mathrm{p}<0.05)$.

\section{DISCUSSION}

This study reports for the first time, the repeatability of ocular surface sensitivity to mechanical stimulation of the ocular surface, using air stimuli delivered at eye and room temperature using a modified Belmonte aesthesiometer and the effects of short term contact lens wear on ocular surface sensitivity.

Diurnal variations in sensitivity were shown for both inferior and central corneal locations, with a higher sensitivity demonstrated in the afternoon compared to the morning for stimuli delivered at eye temperature. Diurnal variation was not observed for measurement of conjunctival sensitivity or for any stimuli delivered at room temperature. The diurnal variation in central corneal sensitivity in the present study was $13 \%$ compared with $28 \%$ in a study using the Cochet-Bonnet aesthesiometer. ${ }^{22}$ Diurnal variation to stimuli delivered using an air jet aesthesiometer was 35\% over a 24 hour period. ${ }^{23}$ Reduced sensitivity upon awakening has been attributed to reduced oxygen tension at the epithelial surface during eye closure, and the degree of reduction in sensitivity is related to the duration of eye closure. ${ }^{24}$ Animal studies have shown that a similar relation and corneal sensitivity reduction following overnight eye closure appear to occur in conjunction with a reduction in corneal epithelial acetylcholine and choline acetyltransferase activity. ${ }^{25}$ The conjunctiva is likely to be less susceptible to the effects of hypoxia because of its vascular nature; therefore, the lack of a demonstrable hypoxia induced diurnal variation in mechanical sensitivity is not unexpected. However, the power to detect diurnal variations in conjunctival sensitivity was low in the present study.

Day to day variations in corneal and conjunctival sensitivity were small using this technique. There were no significant differences in mechanical thresholds between days and no obvious learning effect occurred; however, the observed power to detect differences was small (0.20 to 0.52$)$. This lack of day to day variation is consistent with other gas aesthesiometry techniques. ${ }^{18} 26$

Significant differences were shown between the ocular sites, with the cornea showing higher sensitivity than the conjunctiva. Multiple range testing showed that the site differences were significant only for eye temperature stimuli. Similar findings have been reported using comparable gas aesthesiometry techniques. ${ }^{27}$ Site related differences have been demonstrated using the Cochet-Bonnet aesthesiometer, where regions of the conjunctiva have been shown to be up to $3 \log$ units less sensitive than the central cornea. ${ }^{11}{ }^{28}$ However, the magnitude of the difference between the sites in sensitivity to air jet mechanical stimuli in the present study and in earlier reports ${ }^{18} 27$ appears to be reduced in comparison. This may be the result of site related differences in the type and distribution of nociceptors and stimulus characteristics. Animal electrophysiological studies suggest that high pressure mechanoreceptors, which would be exclusively stimulated by a pure mechanical stimulus, tend to be located in the central cornea. ${ }^{32}{ }^{30}$ Human and animal ultrastructural studies have shown that corneal free nerve endings show structural and functional specialisation. ${ }^{30}{ }^{31}$ A $\delta$ fibres responding to mechanical stimulation have small receptive fields, elongated structure running parallel to the ocular surface, and exhibit directional selectivity. Conversely, polymodal receptors and low pressure mechanoreceptors with larger receptive fields are distributed throughout the cornea and conjunctiva. C fibres responding to polymodal stimuli run perpendicular to the ocular surface.

Differences in sensitivity between the ocular sites were not significant for stimuli delivered at room temperature in this study. Mechanical thresholds for stimuli delivered at ambient temperature were significantly lower than those delivered at eye temperature, which is consistent with previous reports. ${ }^{20}$ Limited $^{18}$ or no differences ${ }^{32}$ in sensitivity between the cornea and conjunctiva have been reported previously for gas aesthesiometers delivering thermally cooling stimuli, which effect cooling of the tear film. Energy transfer from the underlying tissue to the tear film is detected by the sensory nerves. ${ }^{33}$ Both the cornea and conjunctival sensory nerves appear to have high sensitivity to stimuli with both thermally cooling and mechanical effects (table 2). Using a pure thermal stimulus, the cornea appears to be less sensitive than the conjunctiva. ${ }^{34}$ However, the intensity of perceived sensation with suprathreshold thermal stimuli appears to be similar in the cornea and conjunctiva. ${ }^{35} \mathrm{C}$ fibres responding to thermal stimuli are found in exposed areas of the eye, such as the cornea, limbus, and bulbar conjunctiva and tend to have large overlapping receptive fields. ${ }^{36}$ In ocular sites not exposed to external temperature changes, such as the sclera and episclera, sensory fibres appear to respond to change in temperature associated with increased or decreased blood flow. ${ }^{37}$ It is conceivable that fibres in the limbus and conjunctiva have a similar role.

Table 3 Mean threshold values $(\mathrm{ml} / \mathrm{min}$ ) for lens wear conditions

\begin{tabular}{lllll}
\hline & No wear & Etafilcon A wear & Lotrafilcon wear & p Value (ANOVA) \\
\hline Central cornea & $76.5(30)$ & $74.9(27.3)$ & $60.2(29.7)$ & NS \\
Inferior cornea & $86.8(35.1)$ & $81.7(30.0)$ & $74.1(32.6)$ & NS \\
Inferior conjunctiva & $126.6(43.3)$ & $116.6(36.2)$ & $85.2(22.8)$ & $<0.05$ \\
\hline NS = not significant. & & & & \\
\hline
\end{tabular}


Significant differences in threshold were observed between the two stimulus temperatures tested (tables 1 and 2). Thresholds were lower, indicating that the ocular surface was more sensitive to stimuli delivered at a lower temperature. This finding is entirely consistent with the expectation that lower temperature stimuli elicit both a mechanical and thermally cooling response, ${ }^{18}{ }^{26}$ through stimulating mechanical, polymodal and cold nociceptors and resulting in a lower air pressure being required to elicit a threshold response.

Short term wear of hydrogel and silicone hydrogel lenses in unadapted subjects appears to have no effect on corneal sensitivity in this study. Previous reports on the effects of short term wear in adapted daily contact lens wearing subjects have indicated that corneal sensitivity is either slightly reduced following 8-12 hours wear of hydrogel lenses $^{638}$ or shows no change. ${ }^{39}$ The observed reduction has been attributed to corneal oedema causing a metabolic alteration. ${ }^{638}$ One interesting observation not previously reported is the increased sensitivity of the bulbar conjunctiva following short term wear of silicone hydrogel lenses. A similar change was not observed with hydrogel lenses. Conjunctival and limbal sensitivity is mediated primarily through the low threshold mechanical and polymodal fibres. ${ }^{2}$ In response to sustained mechanical pressure, unmyelinated C polymodal fibres will continue to fire, with an irregular tonic discharge. ${ }^{36}$ It is conceivable that lenses of high modulus may provide a chronic low grade stimulus to the inferior ocular surface, possibly as a result of mechanical pressure or lens edge configuration effects; however, further study with a larger sample size is required to confirm this effect and to examine the impact of lens wear on regional conjunctival sensitivity.

In summary, the modified Belmonte aesthesiometer permits reasonably repeatable measurement of the mechanical sensitivity of the cornea and conjunctiva, Mechanical threshold measurements are consistent with previously reported techniques; however, we believe that this technique allows elucidation of mechanical fibre responses both with and without the influence of thermal component.

\section{ACKNOWLEDGEMENTS}

This study was supported by the Australian Government through the Australian Research Council Collaborative Grants Scheme, the Cooperative Research Centres Scheme and by Allergan Ltd.

\section{Authors' affiliations}

F Stapleton, M E Tan, E B Papas, K Ehrmann, B Golebiowski,

B A Holden, Cornea and Contact Lens Research Unit, School of Optometry and Vision Science and Vision CRC, University of New South Wales, Sydney, New South Wales, 2052, Australia

J Vega, CCLR, School of Optometry, University of Waterloo, Canada

Grant support: The study was partly supported by the Australian Federal Government through the Cooperative Research Centres Programme and through the Australian Research Council Collaborative Grants Programme and by Allergan Ltd.

Proprietary interest: None.

\section{REFERENCES}

1 Bron AJ, Tripathi RC, Tripathi BJ. The cornea and sclera. In: Bron AJ, Tripathi RC, Tripathi BJ, eds. Wolff's anatomy of the eye and orbit.8th ed. London: Chapman and Hall, 1997:233-71.

2 Belmonte C, Garcia-Hirschfeld J, Gallar J. Neurobiology of ocular pain. Prog Ret Eye Res 1997; 16:117-56.

3 Tanelian DL, Beverman RW. Responses of rabbit corneal nociceptors to mechanical and thermal stimulation. Exp Neurol 1984;84:165-78.

4 Beuerman RW, McCulley JP. Comparative clinical assessment of corneal sensation with a new aesthesiometer. Am J Ophthalmol 1978;86:812-15.
5 Kanellopoulos AJ, Pallikaris IG, Donnenfield ED, et al. Comparison of corneal sensation following photorefractive keratectomy and laser in situ keratomileusis. J Cataract Refract Surg 1997;23:34-8.

6 Millodot M. Effect of soft lenses on corneal sensitvity. Acta Ophthalmol 1974:52:603-8.

7 Millodot M. Effect of long-term wear of hard contact lenses on corneal sensitivity. Arch Ophthalmol 1978;96:1225-7.

8 Von Frey M. Berichte uber die verhaindlungen der koniglich sachsichen. Ges Wiss 1894;46:185-96.

9 Boberg-Ans J. Experience in clinical examination of corneal sensitivity and the nasolacrimal reflex after retrobulbar anaesthesia. $\mathrm{Br} J$ Ophthalmol 1955;39:705-26.

10 Cochet P, Bonnet R. L'esthesie corneenne. La Clin Ophtalmol 1960;4:3-27.

11 Norn MS. Conjunctival sensitivity in normal eyes. Acta Ophthalmol 1973;51:58-66.

12 Millodot M, Larson W. Effect of bending the nylon thread of the Cochet Bonnet aesthesiometer upon the recorded pressure. Contact Lens 1967;1:5-7.

13 Brennan NA, Bruce AS. Aesthesiometry as an indicator of corneal health. Optom Vis Sci 1991;68:699-702.

14 Murphy PJ, Patel S, Marshall J. A new non-contact corneal aesthesiometer (NCCA). Ophthal Physiol Opt 1996;16:101-7.

15 Beverman RW, Maurice DM, Tanelian DL. Thermal stimulation of the cornea. In: Anderson, Matthews, eds. Pain in the trigeminal region. Amsterdam: Elsevier/North-Holland, Biomedical Press, 1977.

16 Brennan NA, Maurice DM. Corneal aesthesiometry with a carbon dioxide laser. Invest Ophthalmol Vis Sci [Suppl], 1989;30:S148.

17 Weinstein S, Drozdenko R, Weinstein C. A new device for corneal esthesiometry: clinical significance and application. Clin Eye Vis Care 1992;4:123-8.

18 Vega JA, Simpson TL, Fonn D. A noncontact pneumatic esthesiometer for measurement of ocular sensitivity: a preliminary report. Cornea 1999;18:675-81.

19 Dupuy B, Thompson H, Beuerman R. Capsaicin: a psychophysical tool to explore corneal sensitivity. Invest Ophthalmol Vis Sci [Suppl] 1988;29:454

20 Belmonte C, Acosta MC, Schmelz M, et al. Measurement of corneal sensitivity to mechanical and chemical stimulation with a $\mathrm{CO}_{2}$ esthesiometer. Invest Ophthalmol Vis Sci 1999;40:513-19.

21 Stapleton F, Tan ME, Vega J, et al. Repeatability of measurement of corneal and conjunctival sensitivity. Invest Opthalmol Vis Sci [Suppl], 1999;40:S338.

22 Millodot M. Diurnal variation of corneal sensitivity. $\mathrm{Br} J$ Ophthalmol 1972;56:844-7.

23 Du Toit R, Vega JA, Fonn D, et al. Diurnal variation of corneal sensitivity and thickness. Cornea 2003;22:205-9.

24 Millodot $M, O^{\prime}$ Leary DJ. Loss of corneal sensitivity with lid closure in humans. Exp Eye Res 1979;29:417-21.

25 Mindel JS, Szilagyi PIA, Zadunaisky JA, et al. The effects of blephorrhaphy induced depression of corneal cholinergic activity. Exp Eye Res 1979;29:463-8.

26 Murphy PJ, Lawrenson JG, Patel S, et al. Reliability of the non-contact corneal aesthesiometer and its comparison with the Cochet-Bonnet aesthesiometer. Ophthal Physiol Opt 1998;18:532-39.

27 Feng Y, Simpson TL. Nociceptive sensation and sensitivity evoked from the human cornea and conjunctiva stimulated by CO2. Invest Ophthalmol Vis Sci 2003;44:529-32.

28 Drager J. Corneal sensitivity: measurement and clinical importance. Vienna: Springer Verlag, 1984.

29 Belmonte C, Gallar J, Pozo MA, et al. Excitation by irritant chemical substances of sensory afferent units in the cat's cornea. J Physiol 1991;437:709-25.

30 Maclver MB, Tanelian DL. Structural and functional specialisation of A delta and $C$ fiber free nerve endings innervating rabbit corneal epithelium. J Neurosci 1993;13:4511-24.

31 Muller L, Pels L, Vrensen GFJM. Ultrastructural organization of human corneal nerves. Invest Ophthalmol Vis Sci 1996;37:476-88.

32 Murphy PJ, Armstrong E, Woods LA. A comparison of corneal and conjunctival sensitivity to a thermally cooling stimulus. Adv Exp Med Biol 2002;506:719-22

33 Murphy PJ, Morgan PB, Patel S, et al. Corneal surface temperature change as the mode of stimulation of the non-contact corneal aesthesiometer. Cornea 1999; 18:333-42.

34 Kenshalo DR. Comparison of thermal sensitivity of the forehead, lip, conjunctiva and cornea. J Appl Physiol 1960;15:987-91.

35 Acosta MC, Tan ME, Belmonte C, et al. Sensations evoked by selective mechanical, chemical and thermal stimulation of the conjunctiva and corrnea. Invest Ophthalmol Vis Sci 2001;42:2063-7.

36 Gallar J, Pozo MA, Tuckett RP, et al. Response of sensory units with unmyelinated fibres to mechanical, thermal and chemical stimulation of the cat's cornea. J Physiol 1993;468:609-22.

37 Gallar J, Acosta MC, Belmonte C. Activation of scleral cold thermoreceptors by temperature and blood flow changes. Invest Ophthalmol Visual Sci 2003;44:697-705

38 Velasco MJ, Bermudez FJ, Romero J, et al. Variations in corneal sensitivity with hydrogel contact lenses. Acta Ophthalmol 1994;72:53-6.

39 Knoll HA, Williams J. Effects of hydrophilic contact lenses on corneal sensitivity. Am J Optom Am Arch Optom 1970;47:561-3. 